\title{
Effect analysis of kinetic energy progressive exercise in patients with acute myocardial infarction after percutaneous coronary intervention: a randomized trial
}

\author{
Minghui Jiang ${ }^{1 \#}$, Mei Hua ${ }^{2 \#}$, Xueping Zhang ${ }^{2}$, Liuqing $\mathrm{Qu}^{2}$, Lina Chen ${ }^{2}$ \\ ${ }^{1}$ Department of Cardiology, Xuzhou Central Hospital, Xuzhou, China; ${ }^{2}$ Department of Coronary Care Unit, Xuzhou Central Hospital, Xuzhou, \\ China \\ Contributions: (I) Conception and design: M Jiang, L Qu, L Chen; (II) Administrative support: L Qu, L Chen; (III) Provision of study materials or \\ patients: M Jiang, M Hua, X Zhang; (IV) Collection and assembly of data: M Jiang, M Hua, X Zhang; (V) Data analysis and interpretation: M Jiang, \\ L Qu, L Chen; (VI) Manuscript writing: All authors; (VII) Final approval of manuscript: All authors. \\ \#These authors contributed equally to this work. \\ Correspondence to: Lina Chen; Liuqing Qu. Department of Coronary Care Unit, Xuzhou Central Hospital, Xuzhou 221009, China. \\ Email: Chenlinax@163.com; 1104099592@qq.com.
}

Background Acute myocardial infarction (AMI) is the most common critical illness clinically. Percutaneous coronary intervention (PCI) can help patients with AMI by reopening their blocked blood vessels and improving clinical symptoms. Clinical practice has confirmed that rehabilitation training after PCI could significantly promote the recovery of patients' heart function, reduce cardiovascular events, and have a positive significance for prognosis. This study aimed to explore the effect of kinetic energy progressive exercise (PEKE) applied to patients with AMI after PCI.

Methods: From April 2019 to April 2020, a total of 98 patients with AMI after PCI in our hospital were randomly allocated to PEKE group and routine intervention (RI) group. The RI group adopted routine intervention, while the PEKE group introduced PEKE intervention on the basis of the RI group. The incidence of adverse events (AEs), motor function, cardiac function, and quality of life (QoL) before and after intervention were compared between the two groups.

Results: Compared with the RI group, the incidence of AEs in the PEKE group was significantly reduced $\left(\chi^{2}=4.404, \mathrm{P}=0.036\right)$. After 6 months of intervention, the maximum exercise load and metabolic equivalent of the PEKE group were greater than those of the RI group ( $t=7.114,4.565 ; \mathrm{P}=0.000,0.000)$. After 6 months of intervention, the left ventricular ejection fraction (LVEF) of the PEKE group was greater than that of the RI group ( $\mathrm{t}=6.826, \mathrm{P}=0.000)$, and there were no significant differences in left ventricular end-diastolic volume (LVEDV) and left ventricular end-systolic volume (LVESV) compared with the RI group ( $\mathrm{t}=1.253,1.147$; $\mathrm{P}=0.213$, 0.254). After 6 months of intervention, the PEKE group's symptoms, physical function, cognitive function, psychosocial function, and satisfaction scores were greater than those in the RI group ( $\mathrm{t}=5.991$, 4.612, 7.165, 5.731, 5.468; $\mathrm{P}=0.000,0.000,0.000,0.000,0.000)$.

Conclusions: We applied PEKE was to AMI patients with after PCI, and it was shown to effectively reduce AEs, improve the patients' exercise ability and cardiac function, and improve their QoL.

Trial Registration: ClinicalTrials.gov Identifier: ChiCTR2100046123.

Keywords: Progressive exercise of kinetic energy (PEKE); acute myocardial infarction (AMI); percutaneous coronary intervention (PCI); quality of life (QoL)

Submitted May 10, 2021. Accepted for publication Jun 29, 2021.

doi: $10.21037 /$ apm-21-1478

View this article at: https://dx.doi.org/10.21037/apm-21-1478

(c) Annals of Palliative Medicine. All rights reserved. 


\section{Introduction}

Acute myocardial infarction (AMI) is the most common clinically critical illness. Currently, China has 290 million patients with cardiovascular diseases, and it is estimated that by 2030 , the number of patients with acute myocardial infarction will reach 22.6 million (1).Percutaneous coronary intervention (PCI) can help to reopen the blocked blood vessels and improve clinical symptoms of AMI patients (2). Nuding et al. reported that although better treatment effects could be obtained after PCI, about $25 \%$ of patients still do not regain normal body functions, which seriously impacts on their physical and mental health (3). Kim et al. asserted that PCI cannot change the pathological basis of atherosclerosis; so even after PCI treatment, the risk of coronary artery restenosis would remain the same (4). It has been confirmed through clinical practice that rehabilitation training after PCI could significantly promote the recovery of heart function, reduce cardiovascular events, and have a positive significance for prognosis (5). Andjic et al. found that short-term exercise training could improve the cardiac function of patients with AMI after PCI (6), but the effect of progressive exercise of kinetic energy (PEKE) on AMI after PCI has not been reported. PEKE is a new type of rehabilitation exercise, which places central focus on the disease and develops correspondingly dynamic targeted care (7); however, there have been very few related studies in China (8). In this study, PEKE was applied to patients with AMI after they had undergone PCI, and the incidence of adverse events (AEs), motor function, cardiac function, and quality of life (QoL) were examined. We present the following article in accordance with the CONSORT reporting checklist (available at https://dx.doi. org/10.21037/apm-21-1478).

\section{Methods}

\section{Patient selection}

This paper was a comparative study of two parallel intervention measures of patients with AMI after PCI, and allocation ratio is $1: 1$. A total of 98 patients with AMI after PCI who were admitted to the Xuzhou Central Hospital from April 2019 to April 2020 were selected. These patients were randomly divided into PEKE group $(n=49)$ and routine intervention (RI) group $(n=49)$. The inclusion criteria were as follows: (I) met the diagnostic criteria for AMI; (II) received PCI for the first time; (III) absence of mental disorders and had good communication skills; (IV) aged $\geq 18$ years old; (V) written informed consent was provided by the patients or their family members on their behalf. The exclusion criteria were as follows: (I) incomplete medical records were; (II) comorbidity of severe liver, kidney, lung, or other important organ diseases; (III) patient history of mental illness; (IV) inability to participate in postoperative follow-up or withdrawal from the study halfway. The study was approved by the Ethics Committee of Xuzhou Central Hospital (KYLC2018162), and conducted in accordance with the Declaration of Helsinki (as revised in 2013). All participants provided informed consent.

\section{Interventions}

The RI group received routine care. After the patient was admitted to hospital, the nursing staff distributed health education materials to the patient and their family members, prepared the patient preoperatively in accordance with the requirements of the department, guided the patient to get out of bed after the operation, conducted sports education before leaving the hospital, and instructed patients to return to the clinic at the scheduled time.

The PEKE group was introduced to PEKE on the basis of the RI group. (I) Within 1 week after the operation, the nursing staff assisted the patient to eat in bed, wash, excrete, turn over, and so on. In addition, the nursing staff demonstrated and instructed the patient to start the training of alternating between fast and slow breathing at the bedside, 5-6 times/min for $10 \mathrm{~min}$. (II) On the 8 th day after the operation, the nursing staff continued to perform breathing exercises with the patient. After the patient's condition was basically stable, 3 types of stretching exercises were selected according to their individual preferences, for $5 \mathrm{~min} /$ time. When the patient reached tolerance of the above training, increased strength training was added, such as squatting, weight-bearing exercises, and so on, 10 repetitions/set, 3 sets/d. Patients with orthostatic hypotension cannot perform squatting exercises and thus were not requested to do so. (III) The degree of recovery of the patient's heart function was determined, and endurance exercises were increased as appropriate, including upper and lower limb training. Upper limb training involved raising the arms up high and outlining left and right cycles, with 15 cycles in each repetition, and 3 repetitions in each set. Lower limb exercises began with walking $100 \mathrm{~m}$ on flat ground, and the intensity was gradually increased to walking 
$150 \mathrm{~m}$ on flat ground after climbing and descending 1-2 flights of stairs. Once the patient had reached their limit, they returned to the previous training intensity, and waited until their condition stabilized before transitioning back to the higher intensity.

The duration of continuous intervention for both participant groups was 6 months.

\section{Evaluation indexes}

\section{The incidence of AEs}

Intervention staff inquired about and recorded whether the patient had muscle soreness, palpitations, chest tightness, dizziness, shortness of breath, and other symptoms during the intervention period, and calculated the total incidence of AEs.

\section{Motor function}

Intervention staff detected and recorded participants' maximum exercise load and metabolic equivalent during early exercise and 6 months after intervention. Nursing staff instructed patients to record motor function index data once a week by means of stopwatch and weekly chart of medical measurement, and to fill in the medical record form issued by the hospital. The nursing staff calculated the average value during the follow-up visit.

\section{Cardiac function}

The Philips GK5500 cardiac color Doppler ultrasound system (Philips Healthcare, Amsterdam, Netherlands) was used to detect the left ventricular end diastolic volume (LVEDV), left ventricular end systolic volume (LVESV), and left ventricular ejection fraction (LVEF) before and 6 months after the intervention.

\section{QoL}

The coronary revascularization outcome questionnaire for determination of quality (CROQ-PTCA-Post) was used to assess the changes in the QoL of participants before and 6 months after intervention (9). The CROQ-PTCAPost includes 5 dimensions: symptoms, physical function, cognitive function, psychosocial function, and satisfaction, all of which are scored on a 100-point scale, with a higher the score indicating a higher quality of the corresponding dimension.

Cardiac function and QOL were the primary outcomes we analyzed in this study, while Incidence of AEs and Motor function were the secondary outcomes.

\section{Statistical analyses}

SPSS 20.0 (SPSS Inc., Chicago, IL, USA) was used for the statistical analysis of this study. Motor function, cardiac function, and QoL were expressed as mean \pm standard deviation $\left(\bar{x}_{ \pm} \mathrm{SD}\right)$. 2 -tailed $t$-tests was used for comparison before and after intervention between PEKE group and RI group. The incidence of AEs was expressed by rates and percentages. The chi-squared $\left(\chi^{2}\right)$ test or rank-sum test was used for comparison between PEKE group and RI group. $\mathrm{P}<0.05$ was considered statistically significant.

\section{Results}

\section{General information}

This study included 98 patients with AMI after PCI from April 2019 to April 2020. The duration of continuous intervention for both participant groups was 6 months. The RI group included 33 males and 16 females, aged $32-75$ years old, with an average age of $59.62 \pm 8.98$ years. In relation to level of education, 9 cases were at the level elementary school and below, 20 were junior high school, 12 were high school or technical secondary school, and 8 had attended junior college and above. In relation to marital status, the number of participants in the marriage was 30 , and the number of participants in unmarried/divorced/ widowed was 19 . In relation to family income, the number of participants whose income less than 4,000 yuan per month was 5 cases, 4,000-8,000 yuan was 24 cases, and more than 8,000 yuan was 20 cases. In relation to puncture site, 18 cases were femoral artery, and 31 cases were radial artery. In relation to comorbidities, 28 participants had high blood pressure, and 20 had diabetes. In relation to cardiac function classification, 30 participants were level II, and 19 were level III. The PEKE group included 31 males and 18 females, aged 33-78 years old, with an average age of $58.79 \pm 9.36$ years. Regarding level of education, 10 participants had attended elementary school and below, 19 were at the level of junior high school, 13 were high school or technical secondary school, and 7 cases had attended junior college and above. In relation to marital status, the number of participants in the marriage was 32 , and the number of participants in unmarried/divorced/widowed was 17 . In relation to family income, the number of participants whose income less than 4,000 yuan per month was 5 cases, 4,000-8,000 yuan was 26 cases, and more than 8,000 yuan was 18 cases. In relation to puncture site, 20 cases were femoral artery, and 29 cases were radial artery. 


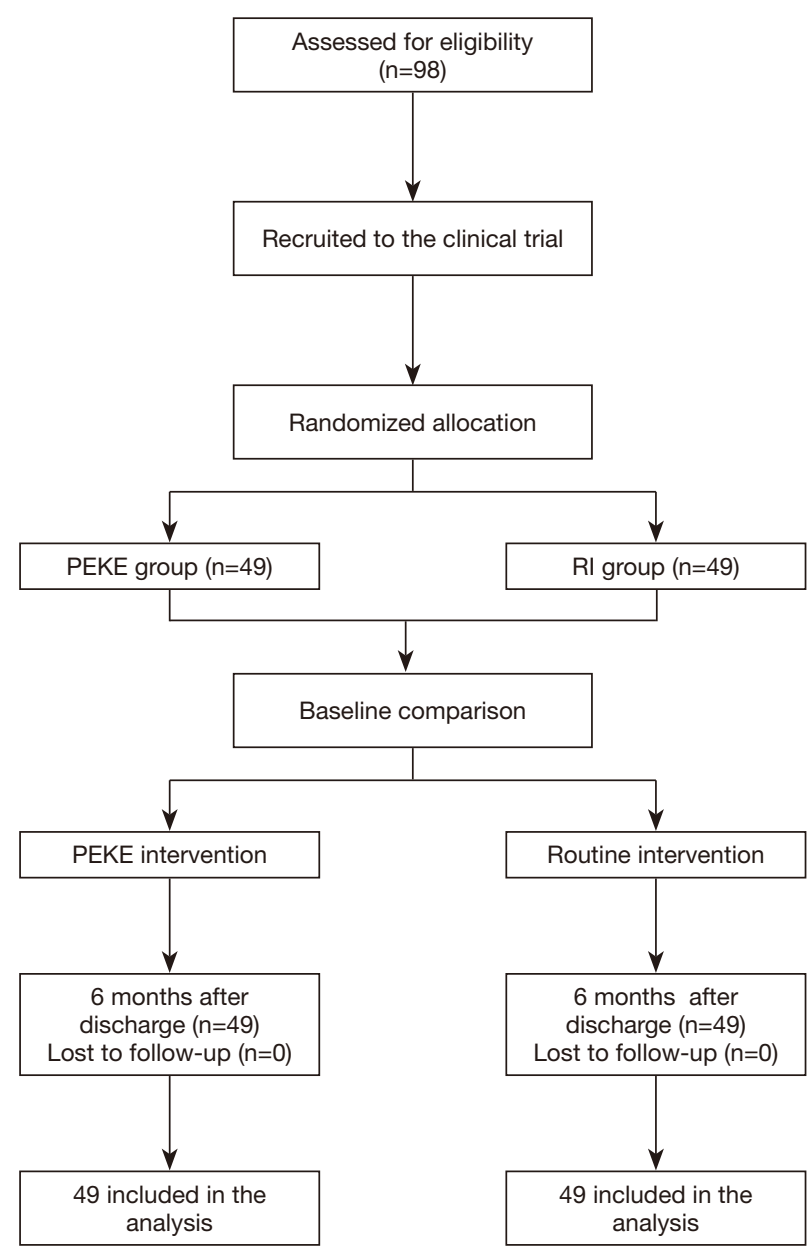

Figure 1 Study flow chart. PEKE, progressive exercise of kinetic energy; RI, routine intervention.

In relation to comorbidities, 30 participants had high blood pressure and 21 had diabetes. In relation to cardiac function classification, 27 participants were level II and 22 cases were level III (Figure 1).

There were no differences in gender, age, education level, marital status, puncture site, comorbidities, cardiac function and family income between the two participant groups $(\mathrm{P}>0.05)$ (Table 1).

\section{The incidence of AEs}

In the PEKE group, there was 1 case of palpitations and chest tightness, and the $\mathrm{AE}$ rate was $2.04 \%$. In the $\mathrm{RI}$ group, there were 3 cases of muscle soreness, 2 cases of palpitations and chest tightness, 1 case of dizziness, and 2 cases of shortness of breath, and the incidence rate of AEs was $16.33 \%$. Compared with the RI group, the incidence of AEs in the PEKE group was significantly reduced $\left(\chi^{2}=4.404\right.$, $\mathrm{P}=0.036)$ (Table 2).

\section{Motor function}

During early exercise, there were no statistically significant differences in the maximum exercise load and metabolic equivalent between the PEKE group and the RI group $(\mathrm{t}=0.320,0.090$, respectively; $\mathrm{P}=0.750,0.929$, respectively). After 6 months of intervention, the maximum exercise load and metabolic equivalent of the PEKE group were higher than those of the RI group ( $\mathrm{t}=7.114,4.565 ; \mathrm{P}=0.000,0.000)$ (Table 3).

\section{Cardiac function}

Some representative ultrasonography images of two patients are presented in Figure 2. Before intervention, there were no significant differences in LVEDV, LVESV, and LVEF between the observation and RI groups $(t=0.106,0.027$, 0.167 , respectively; $\mathrm{P}=0.916,0.979,0.868$, respectively). After 6 months of intervention, the LVEF of the PEKE group was higher than that of the RI group ( $t=6.826$, $\mathrm{P}=0.000$ ), while differences in the LVEDV and LVESV between the two groups were not significantly different $(\mathrm{t}=1.253,1.147$, respectively; $\mathrm{P}=0.213,0.254$, respectively) (Table 4).

\section{QoL}

Before the intervention, there were no significant differences in the scores of symptoms, physical function, cognitive function, psychosocial function, and satisfaction between the observation and RI groups $(\mathrm{t}=0.310,0.310$, $0.579,0.543,0.941$, respectively; $\mathrm{P}=0.757,0.757,0.564$, $0.588,0.349$, respectively). After 6 months of intervention, the scores of symptoms, physical function, cognitive function, psychosocial function, and satisfaction of the PEKE group were higher than those of the RI group $(\mathrm{t}=5.991,4.612,7.165,5.731,5.468$, respectively; $\mathrm{P}=0.000$, 0.000, 0.000, 0.000, 0.000, respectively) (Table 5).

\section{Discussion}

The characteristics of AMI include rapid morbidity and high mortality. The key to improving the prognosis of AMI is the restoration of myocardial blood oxygen supply 
Table 1 General information of participants: RI group and PEKE group (n, \%)

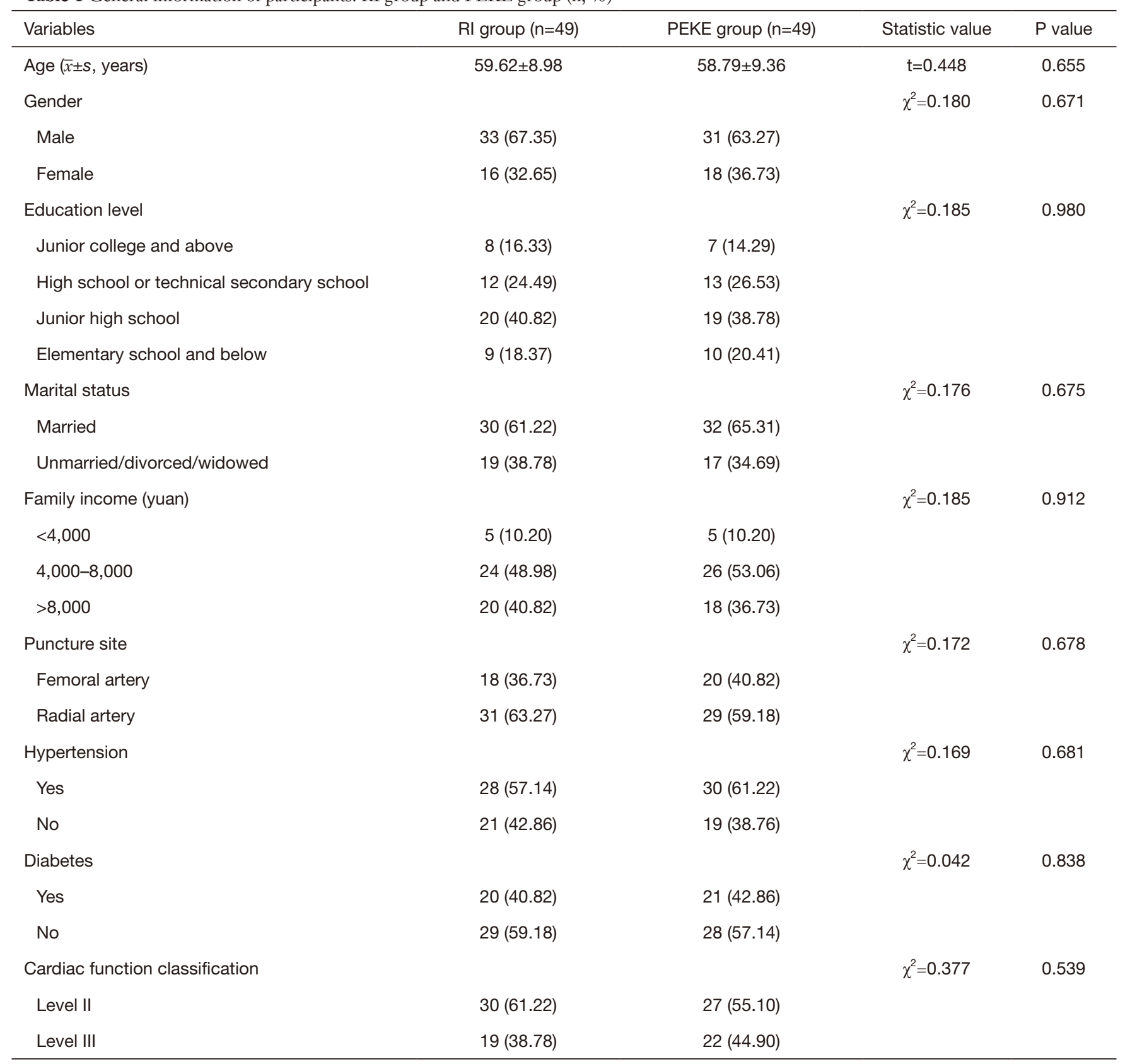

$\mathrm{RI}$, routine intervention; PEKE, progressive exercise of kinetic energy.

Table 2 The incidence of AEs of participants: RI group and PEKE group (n, \%)

\begin{tabular}{|c|c|c|c|c|c|}
\hline Group & Muscle soreness & Palpitations and chest tightness & Dizziness & Shortness of breath & $\mathrm{AE}$ rate \\
\hline PEKE group $(n=49)$ & $0(0.00)$ & $1(2.04)$ & $0(0.00)$ & $0(0.00)$ & $1(2.04)$ \\
\hline$\chi^{2}$ value & - & - & - & - & 4.404 \\
\hline$P$ value & - & - & - & - & 0.036 \\
\hline
\end{tabular}

$\mathrm{AE}$, adverse events; $\mathrm{RI}$, routine intervention; PEKE, progressive exercise of kinetic energy. 
Table 3 Comparison of motor function between the two groups during early exercise and 6 months after intervention $(\bar{x} \pm s)$

\begin{tabular}{lccc}
\hline Time & Group & Maximum exercise load $(\mathrm{W})$ & ${\text { Metabolic equivalent }\left(\mathrm{mL} \cdot \mathrm{kg}^{-1} \cdot \mathrm{min}^{-1}\right)}$ \\
\hline During early exercise & RI group $(\mathrm{n}=49)$ & $116.82 \pm 32.65$ & $6.83 \pm 1.14$ \\
& PEKE group $(\mathrm{n}=49)$ & $114.73 \pm 31.97$ & $6.85 \pm 1.07$ \\
& $\mathrm{t}$ value & 0.320 & 0.090 \\
& P value & 0.750 & 0.929 \\
6 months after & Rl group $(\mathrm{n}=49)$ & $124.47 \pm 21.59$ & $6.72 \pm 1.26$ \\
intervention & PEKE group $(\mathrm{n}=49)$ & $154.29 \pm 19.87$ & $7.91 \pm 1.32$ \\
& t value & 7.114 & 4.565 \\
& P value & 0.000 & 0.000
\end{tabular}

$\mathrm{RI}$, routine intervention; PEKE, progressive exercise of kinetic energy.

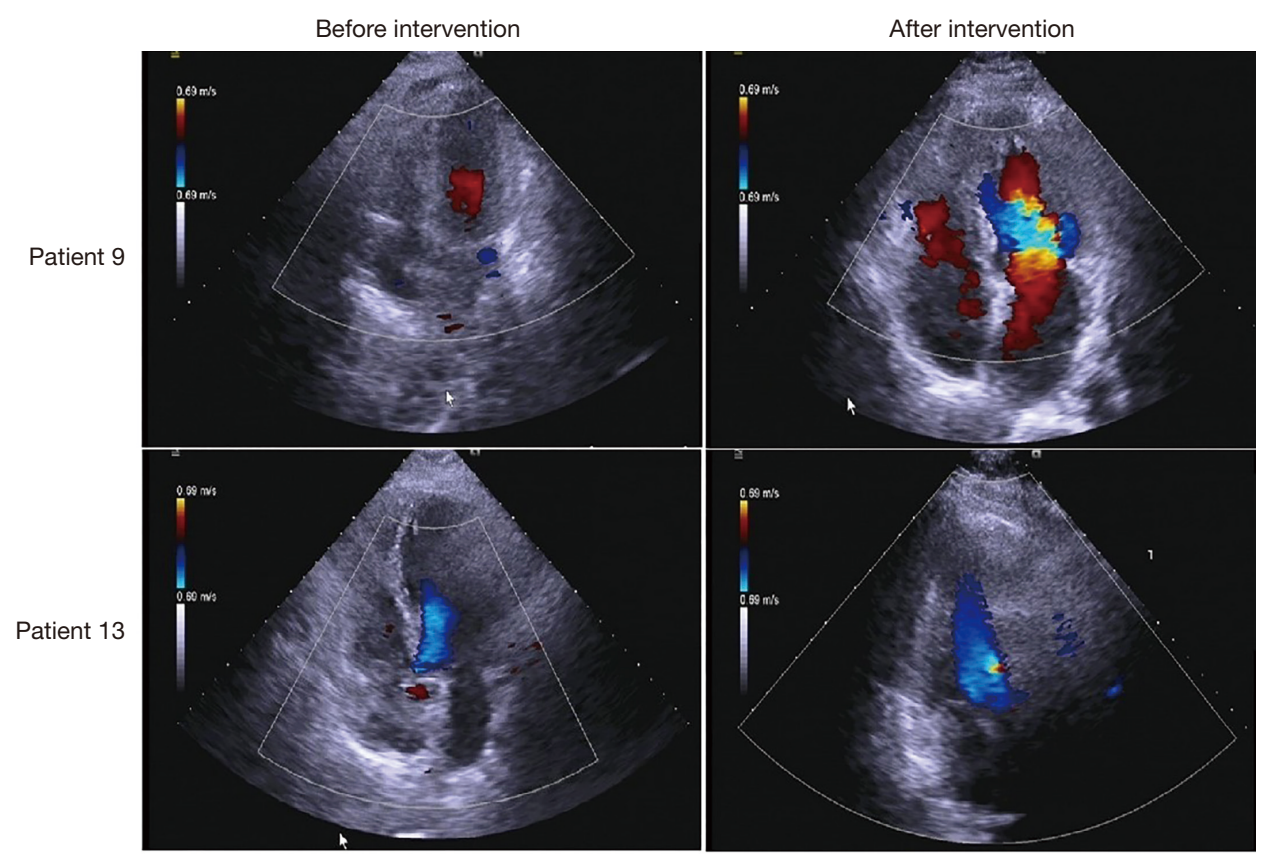

Figure 2 Representative B-mode ultrasonography images.

as soon as possible (10). At present, PCI is generally used to alleviate the clinical symptoms of AMI, by dredging the blocked coronary artery to promote the normal blood oxygen supply of the myocardium (11). However, PCI is a traumatic surgery with some inevitable postoperative complications, which affect the patient's prognosis (12). Studies have shown that post-PCI rehabilitation care could effectively reduce symptoms such as dizziness and shortness of breath, and shorten the patient's hospital stay (13). In recent years, with the widespread promotion of the concept of rehabilitation nursing, various rapid rehabilitation nursing measures have emerged (14). The PEKE program involves a targeted and scientific nursing and is designed according to the characteristics of the disease, with the purpose of promoting postoperative recovery and improving the prognosis of patients (15). In this study, PEKE was used in the care of AMI patients who had undergone PCI treatment and satisfactory results were achieved.

In this study, compared with the RI group, the incidence of AEs in the PEKE group was significantly reduced 
Table 4 Comparison of cardiac function between the two groups before and after intervention $(\bar{x} \pm s)$

\begin{tabular}{|c|c|c|c|c|}
\hline Time & Group & LVEDV (mL) & LVESV (mL) & LVEF (\%) \\
\hline \multirow{3}{*}{ Before intervention } & PEKE group $(n=49)$ & $28.51 \pm 4.18$ & $47.48 \pm 5.38$ & $60.04 \pm 9.13$ \\
\hline & $\mathrm{t}$ value & 0.106 & 0.027 & 0.167 \\
\hline & $P$ value & 0.916 & 0.979 & 0.868 \\
\hline \multirow{3}{*}{ After intervention } & PEKE group $(n=49)$ & $30.58 \pm 3.98$ & $45.18 \pm 4.95$ & $69.62 \pm 5.28$ \\
\hline & $\mathrm{t}$ value & 1.253 & 1.147 & 6.826 \\
\hline & $P$ value & 0.213 & 0.254 & 0.000 \\
\hline
\end{tabular}

RI, routine intervention; PEKE, progressive exercise of kinetic energy; LVEDV, left ventricular end-diastolic volume; LVESV, left ventricular end-systolic volume; LVEF, left ventricular ejection fraction.

Table 5 Comparison of quality of life between the two groups before and after intervention $(\bar{x} \pm s$, points)

\begin{tabular}{|c|c|c|c|c|c|c|}
\hline Time & Group & Symptoms & Physical function & Cognitive function & Psychosocial function & Satisfaction \\
\hline \multirow{3}{*}{$\begin{array}{l}\text { Before } \\
\text { intervention }\end{array}$} & PEKE group $(n=49)$ & $65.24 \pm 14.97$ & $64.52 \pm 11.58$ & $61.83 \pm 11.27$ & $63.56 \pm 11.02$ & $70.64 \pm 10.36$ \\
\hline & $\mathrm{t}$ value & 0.310 & 0.310 & 0.579 & 0.543 & 0.941 \\
\hline & $P$ value & 0.757 & 0.757 & 0.564 & 0.588 & 0.349 \\
\hline \multirow{3}{*}{$\begin{array}{l}\text { After } \\
\text { intervention }\end{array}$} & PEKE group $(n=49)$ & $88.64 \pm 9.72$ & $87.42 \pm 9.36$ & $83.65 \pm 9.47$ & $87.42 \pm 9.36$ & $89.26 \pm 8.41$ \\
\hline & $\mathrm{t}$ value & 5.991 & 4.612 & 7.165 & 5.731 & 5.468 \\
\hline & $P$ value & 0.000 & 0.000 & 0.000 & 0.000 & 0.000 \\
\hline
\end{tabular}

$\mathrm{RI}$, routine intervention; PEKE, progressive exercise of kinetic energy.

$\left(\chi^{2}=4.404, \mathrm{P}=0.036\right)$, showing that PEKE applied to the nursing of AMI patients after PCI could effectively reduce AEs. The main reason may be that early stretching exercises help to reduce the related adverse reactions caused by the extension and bracing of the limbs on the operating side (16).

At the same time, the study showed that compared with the RI group, the maximum exercise load and metabolic equivalent of the PEKE group after 6 months of intervention were greater. $(\mathrm{t}=7.114,4.565 ; \mathrm{P}=0.000$, 0.000). It was revealed that PEKE applied to the nursing of patients with AMI after PCI could effectively improve motor function and promote the return to normal activities. The reason may be that the intervention staff started to instruct patients to perform fast and slow breathing training within 1 week following surgery, which helps to reduce sympathetic nerve activity, and at the same time enhance the regulatory effect of the parasympathetic nerve on the heart, thereby improving the ability of autonomic nerve regulation, and achieving the purpose of improving the body's motor function $(17,18)$.

In this study, the LVEF of the PEKE group was greater than that of the RI group after 6 months of intervention $(\mathrm{t}=6.826, \mathrm{P}=0.000)$, showing that applying PEKE to the nursing of patients with AMI after PCI could effectively improve heart function. The reason may be that PEKE can promote the establishment of cardiac collateral circulation, reduce platelet aggregation, and reduce blood lipids, thereby effectively avoiding thrombosis, and improving myocardial blood supply, ultimately achieving the goal of improving heart function $(19,20)$. In addition, there were no significant differences between LVEDV and LVESV in the observation compared with the RI group ( $t=1.253$, 
$1.147 ; \mathrm{P}=0.213,0.254)$. The reason may be that the number of samples were too small, and the sample size needs to be expanded for further research (21).

In the PEKE group, the symptoms, physical function, cognitive function, psychosocial function, and satisfaction scores were higher than those of the RI group after 6 months of intervention ( $t=5.991,4.612,7.165,5.731,5.468$; $\mathrm{P}=0.000,0.000,0.000,0.000,0.000)$. These findings further showed that PEKE could effectively improve the QoL of patients with AMI after PCI and improve their prognosis. The reason may be that PEKE can help regulate vascular tension, reduce peripheral vascular tension, and improve aortic compliance, so as to achieve the purpose of relieving microvasospasm, restoring normal blood pressure, and ultimately improving the patient's exercise endurance, which encompasses prerequisites for optimizing the QoL $(22,23)$.

\section{Conclusions}

When PEKE was applied to patients with AMI after PCI, it was shown to effectively reduce AEs, improve the patients' exercise and cardiac function, and improve their QoL.

\section{Acknowledgments}

Funding: None.

\section{Footnote}

Reporting Checklist: The authors have completed the CONSORT reporting checklist. Available at https://dx.doi. org/10.21037/apm-21-1478

Trial Protocol: Available at https://dx.doi.org/10.21037/apm21-1478

Data Sharing Statement: Available at https://dx.doi. org/10.21037/apm-21-1478

Conflicts of Interest: All authors have completed the ICMJE uniform disclosure form (available at https://dx.doi. org/10.21037/apm-21-1478). The authors have no conflicts of interest to declare.

Ethical Statement: The authors are accountable for all aspects of the work, including ensuring that questions related to the accuracy or integrity of any part of the work are appropriately investigated and resolved. The study was approved by the Ethics Committee of Xuzhou Central Hospital (KYLC2018162), and conducted in accordance with the Declaration of Helsinki (as revised in 2013). All participants provided informed consent.

Open Access Statement: This is an Open Access article distributed in accordance with the Creative Commons Attribution-NonCommercial-NoDerivs 4.0 International License (CC BY-NC-ND 4.0), which permits the noncommercial replication and distribution of the article with the strict proviso that no changes or edits are made and the original work is properly cited (including links to both the formal publication through the relevant DOI and the license). See: https://creativecommons.org/licenses/by-nc-nd/4.0/.

\section{References}

1. Hu SS, Gao RL, Liu LS, et al. Summary of the 2018 Report on Cardiovascular Diseases in China. Chinese Circulation Journal 2019;34:209-20.

2. Ibanez B, James S, Agewall S, et al. 2017 ESC Guidelines for the management of acute myocardial infarction in patients presenting with ST-segment elevation: The Task Force for the management of acute myocardial infarction in patients presenting with ST-segment elevation of the European Society of Cardiology (ESC). Eur Heart J 2018;39:119-77.

3. Nuding S, Werdan K, Prondzinsky R. Optimal course of treatment in acute cardiogenic shock complicating myocardial infarction. Expert Rev Cardiovasc Ther 2018;16:99-112.

4. Kim Y, Ahn Y, Cho MC, et al. Current status of acute myocardial infarction in Korea. Korean J Intern Med 2019;34:1-10.

5. Wang C, Jing Q. Non-coding RNAs as biomarkers for acute myocardial infarction. Acta Pharmacol Sin 2018;39:1110-9.

6. Andjic M, Spiroski D, Ilic Stojanovic O, et al. Effect of short-term exercise training in patients following acute myocardial infarction treated with primary percutaneous coronary intervention. Eur J Phys Rehabil Med 2016;52:364-9.

7. Brown MK, Poeltler DM, Hassen KO, et al. Incidence of Hypocapnia, Hypercapnia, and Acidosis and the Associated Risk of Adverse Events in Preterm Neonates. Respir Care 2018;63:943-9.

8. Zhang Y, Cao H, Jiang P, et al. Cardiac rehabilitation in 
acute myocardial infarction patients after percutaneous coronary intervention: A community-based study. Medicine (Baltimore) 2018;97:e9785.

9. Orrem HL, Nilsson PH, Pischke SE, et al. Acute heart failure following myocardial infarction: complement activation correlates with the severity of heart failure in patients developing cardiogenic shock. ESC Heart Fail 2018;5:292-301.

10. Yu Y, Wang J, Wang Q, et al. Admission oxygen saturation and all-cause in-hospital mortality in acute myocardial infarction patients: data from the MIMIC-III database. Ann Transl Med 2020;8:1371.

11. Durko AP, Budde RPJ, Geleijnse ML, et al. Recognition, assessment and management of the mechanical complications of acute myocardial infarction. Heart 2018;104:1216-23.

12. Esposito ML, Zhang Y, Qiao X, et al. Left Ventricular Unloading Before Reperfusion Promotes Functional Recovery After Acute Myocardial Infarction. Kapur NK. J Am Coll Cardiol 2018;72:501-14.

13. Liakos M, Parikh PB. Gender Disparities in Presentation, Management, and Outcomes of Acute Myocardial Infarction. Curr Cardiol Rep 2018;20:64.

14. Ibanez B, James S, Agewall S, et al. 2017 ESC Guidelines for the management of acute myocardial infarction in patients presenting with ST-segment elevation. Kardiol Pol 2018;76:229-313.

15. Basir MB, Schreiber T, Dixon S, et al. Feasibility of early mechanical circulatory support in acute myocardial infarction complicated by cardiogenic shock: The Detroit cardiogenic shock initiative. Catheter Cardiovasc Interv
2018;91:454-61.

16. Chen Z, Li C, Lin K, et al. MicroRNAs in acute myocardial infarction: Evident value as novel biomarkers. Anatol J Cardiol 2018;19:140-7.

17. Itier R, Roncalli J. New therapies for acute myocardial infarction: current state of research and future promise. Future Cardiol 2018;14:329-42.

18. Omar S, Morgan GL, Panchal HB, et al. Management of post-myocardial infarction ventricular septal defects: A critical assessment. J Interv Cardiol 2018;31:939-48.

19. Bowles JR, McEwen MM, Rosenfeld AG. Acute Myocardial Infarction Experience Among Mexican American Women. Hisp Health Care Int 2018;16:62-9.

20. Claessen BE, Henriques JPS. Acute myocardial infarction, chronic total occlusion, and cardiogenic shock: the ultimate triple threat. EuroIntervention 2018;14:e252-4.

21. Zhu L, Liu F, Xie H, et al. Diagnostic performance of microRNA-133a in acute myocardial infarction: A metaanalysis. Cardiol J 2018;25:260-7.

22. Regev E, Asher E, Fefer P, et al. Acute myocardial infarction occurring while on chronic clopidogrel therapy ('clopidogrel failure') is associated with high incidence of clopidogrel poor responsiveness and stent thrombosis. PLoS One 2018;13:e0195504.

23. Lu SF, Lu LX, Smith SC Jr, et al. Acute Myocardial Infarction in Patients with Paraplegia: Characteristics, Management, and Outcomes. Am J Med 2018;131:574.e1574.e11.

(English Language Editor: J. Jones)
Cite this article as: Jiang M, Hua M, Zhang X, Qu L, Chen L. Effect analysis of kinetic energy progressive exercise in patients with acute myocardial infarction after percutaneous coronary intervention: a randomized trial. Ann Palliat Med 2021;10(7):78237831. doi: 10.21037/apm-21-1478 